\title{
The Normal Synovium
}

\author{
Malcolm D. Smith ${ }^{*}$
}

Rheumatology Unit, Repatriation General Hospital, Daws Road, Daw Park, South Australia, SA 5041, Australia

\begin{abstract}
This paper describes the structure and function of the normal synovium including the cellular content, nerve and vascular supply and how normal synovium maintains homeostasis within the joint. It is important to understand normal synovium before appreciating the changes that occur in the synovial membrane which leads to the pathology seen in inflammatory arthritides such as Rheumatoid Arthritis.
\end{abstract}

Keywords: Normal synovial membrane, structure, function, nerve supply, vascular supply, alterations in inflammatory arthritis.

\section{INTRODUCTION}

The term synovium refers to the soft tissue lining the spaces of diarthrodial joints, tendon sheaths and bursae. It includes the continuous surface layer of cells (intima) and the underlying tissue (subintima). The intima consists of macrophages and fibroblasts while the subintima includes blood and lymphatic vessels, a cellular content of both resident fibroblasts and infiltrating cells in a collagenous extracellular matrix [1]. Between the intimal surfaces is a small amount of fluid, usually rich in hyaluronan (hyaluronic acid). Together, this structure provides a non-adherent surface between tissue elements. Unlike serosal surfaces which also have non-adherent properties, synovium is derived from ectoderm and does not contain a basal lamina.

The synovium is the central area of pathology in a number of inflammatory joint diseases, including rheumatoid arthritis (RA) and spondyloarthritis (SpA). However our knowledge of the immuno-histochemical architecture of the synovial membrane, particularly in normal subjects, is surprisingly limited. The normal synovial membrane is stated to be a relatively acellular structure consisting of a distinct intimal lining layer of 1-2 cells thickness and a synovial sublining layer. The latter is relatively acellular, containing scattered blood vessels, fat cells, and fibroblasts, with few lymphocytes or macrophages. Typically, the normal synovium contains an intimal layer which is 20$40 \mathrm{~mm}$ thick in cross-section and an areolar subintima which can be up to $5 \mathrm{~mm}$ in thickness. At many sites there is no discrete membrane, especially where subintima consists of fat pad or fibrous tissue. However, often there is considerable variation of the typical normal synovium appearance, including absence of intimal cells [1-3]. Superficial bursae may contain little or no hyaluronan-rich fluid. Ganglia are sacs containing hyaluronan-rich fluid but do not occur at sites of shearing and do not have a typical intima and so may not really be synovial tissue at all. Diseased synovial tissue may lose any recognizable lining

*Address correspondence to this author at the Rheumatology Unit, Repatriation General Hospital, Daws Road, Daw Park, South Australia, SA 5041, Australia; Tel: 618 82751819; Fax: 618 83744276;

E-mail: malcolm.smith@health.sa.gov.au structure and only be definable by its relation to a joint. In patients with inflammatory arthritis, such as RA, the intimal lining layer is usually markedly thickened, mainly due to an increase in CD68 positive macrophages, with a heavily infiltrated subintimal region, containing $T$ and $B$ lymphocytes, plasma cells, and macrophages, associated with stromal oedema and proliferation of blood vessels.

\section{HISTOLOGY OF THE NORMAL SYNOVIUM}

The microscopic anatomy of normal synovial tissue often falls into three main types [1, 4], based on the structure and content of the subintimal layer: fibrous, areolar and adipose (Figs. 1-3). In some areas of the body, the subintima may consist of periosteum, perimysium or even hyaline or fibrocartilage.

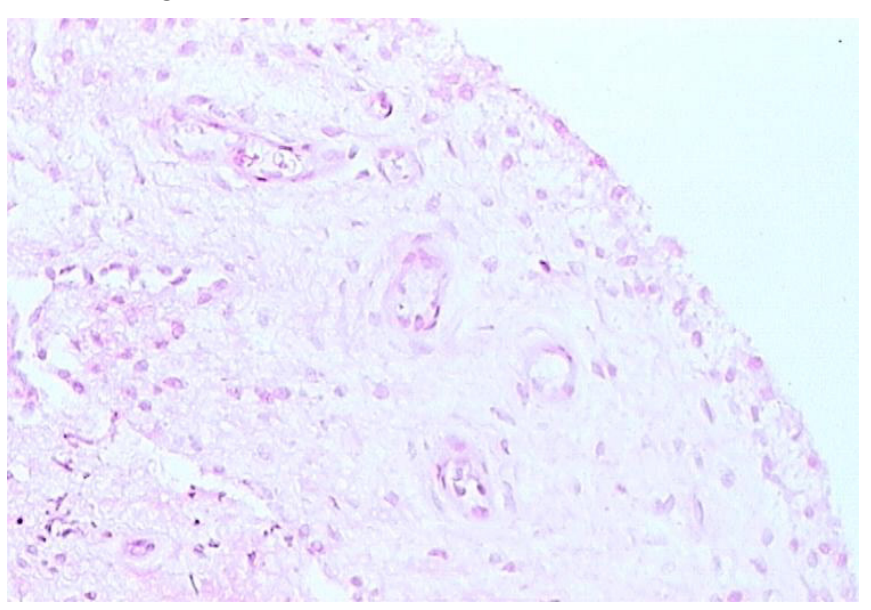

Fig. (1). Areolar form of synovium (H and E stain).

The areolar type of normal synovium is the most specialized form (Fig. 1). It is often crimped into folds, which may disappear when stretched or it may contain projections or villi. There is usually a continuous layer of lining cells often two or three deep on the tissue surface [13]. Immediately beneath these cells are capillaries, with a deeper plexus of small arterioles and venules, associated with mast cells $[5,6]$. Lymphatic vessels are present in all types of normal synovial tissue, although they are infrequent in the fibrous type of normal synovium. The lymphatic vessels are usually found in the deep subintima and fibrous 
layers of normal synovium [7], while in synovium from RA patients lymphatic vessels are widespread and numerous. Nerve fibres are present in synovium usually in association with blood vessels [8]. The connective tissue matrix in normal synovium includes a fine fibrillar matrix with a few type I collagen fibres in the intima' beneath which is a layer relatively rich in type I collagen which forms the physical membrane. The deepest area of the normal synovium consists of a loose connective tissue layer which allows the membrane to move freely. Below this loose layer there will often be found ligament, tendon or periosteum.

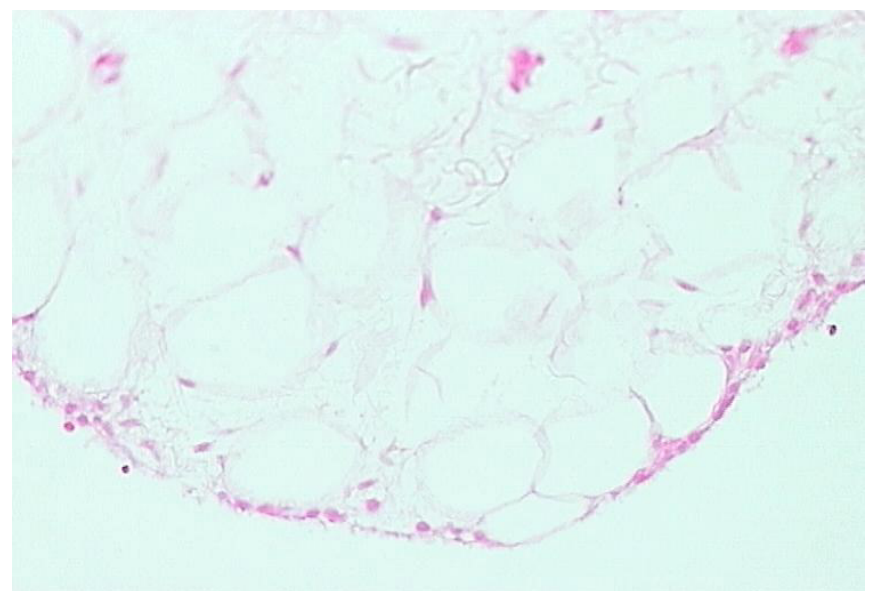

Fig. (2). Adipose form of synovium ( $\mathrm{H}$ and $\mathrm{E}$ stain).

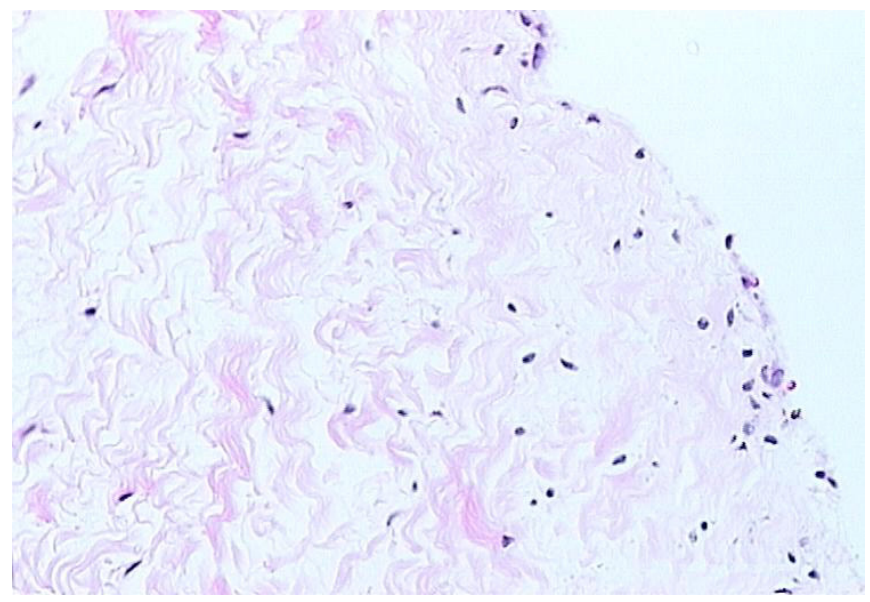

Fig. (3). Fibrous form of synovium (H and $\mathrm{E}$ stain).

Adipose synovium is found mainly in fat pads but is also seen within villi (Fig. 2). There is a complete intimal cell layer and a superficial net of capillaries. The intima may lie directly on adipocytes but is often separated by a band of collagen-rich substratum, while the deeper tissue is fat. Villi usually have a central arteriole and venule but can be avascular. The amount of fat in villi varies and probably decreases with age, with an increase in fibrous tissue.

Fibrous synovium is often difficult to define, consisting of fibrous tissue, such as ligament or tendon, on which lies an intermittent layer of cells (Fig. 3). Fibrous synovium may be indistinguishable from fibrocartilage, especially in the annular pads found in finger joints.

Two types of intimal cell have been defined in normal synovium, utilizing electron microscopy [9]. The type A synoviocyte has cell surface markers identifying it as being from macrophage lineage while the type B synoviocyte is of fibroblast lineage $[1,2,11]$. Type A synoviocytes are probably true macrophages, derived from blood monocytes, while type B synoviocytes are intimal fibroblasts which are locally derived $[1,2]$. In most disease states, such as rheumatoid arthritis, intimal cells increase in number. This is probably due to a number of processes, with macrophage influx from the vascular compartment under cytokine and cell adhesion molecule control being the dominant process $[1-3,10]$.

\section{SYNOVIAL MACROPHAGES}

Macrophages are found both in the intimal and subintimal regions of normal synovium. Intimal macrophages carry typical macrophage lineage markers. They show prominent nonspecific esterase (NSE) activity and are strongly positive for CD163 and CD68 but less so for CD14 (Fig. 4). Intimal macrophages also express the immunoglobulin receptor FcgRIIIa, while subintimal macrophages usually express low levels of FcgRIIIa or are negative [12]. However, macrophages make up a minority of cells in normal intima (Figs. 4, 5), while the numbers in inflammatory arthritis increase dramatically and in RA synovial tissue account for up to $80 \%$ of the intimal layer (Figs. 6, 7). A usual pattern is that of a superficial layer of macrophages with an intimal phenotype below which is a layer of intimal fibroblasts. In the subintima, there may be a zone of NSE-weak, strongly $\mathrm{CD}_{1}{ }^{+} \mathrm{FcgRI}^{+}$macrophages, associated with venules. There may also be a small number of antigen-presenting interdigitating dendritic cells in normal synovium [13, 14]. Evidence to date indicates that both intimal and subintimal macrophages derive from bone marrow via circulating monocytes, many of which probably arrive via subintimal venules and migrate to the intima.

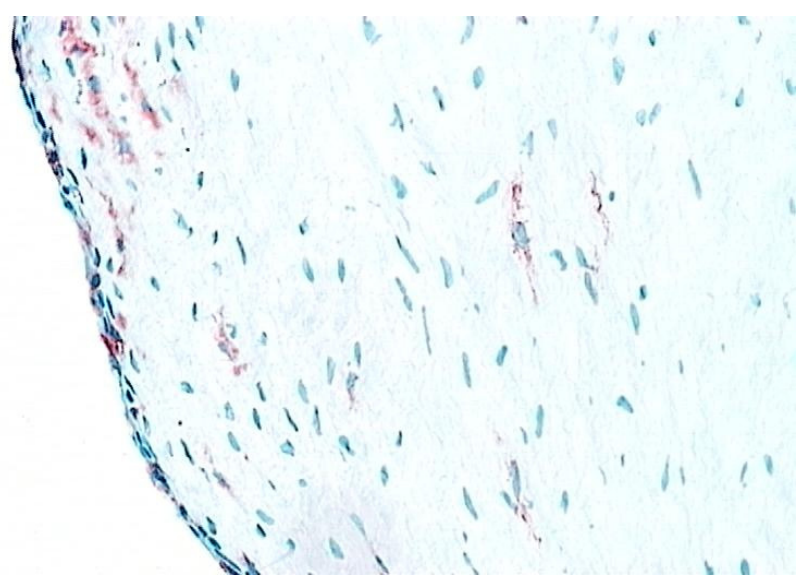

Fig. (4). Synovial macrophages. Normal synovium (X200 magnification) stained for $\mathrm{CD} 68^{+}$macrophages (red) (contrast with Figs. 5, 6).

\section{SYNOVIAL FIBROBLASTS}

Type B synoviocytes have adapted to the production of hyaluronan. $\mathrm{CD}^{-}$intimal fibroblasts alone demonstrate high activity of the enzyme UDP Glucose dehydrogenase (UDPGD) which converts UDP-glucose into UDPglucuronate, one of the two substrates required by hyaluronan synthase for assembly of the hyaluronan polymer [15]. In inflammatory arthritis, UDPGD activity in intimal 


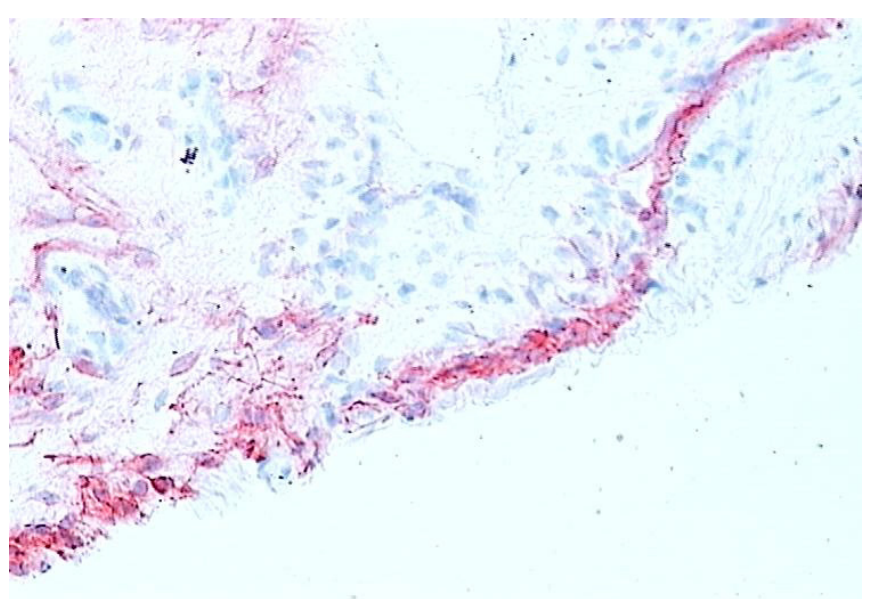

Fig. (5). Normal synovium (X200 magnification) stained for CD55 ${ }^{+}$ fibroblasts (red). Synovial fibroblasts make up most of the cells in the lining layer in the normal synovium intimal layer in contrast to RA synovial tissue (contrast with Figs. 4, 7).

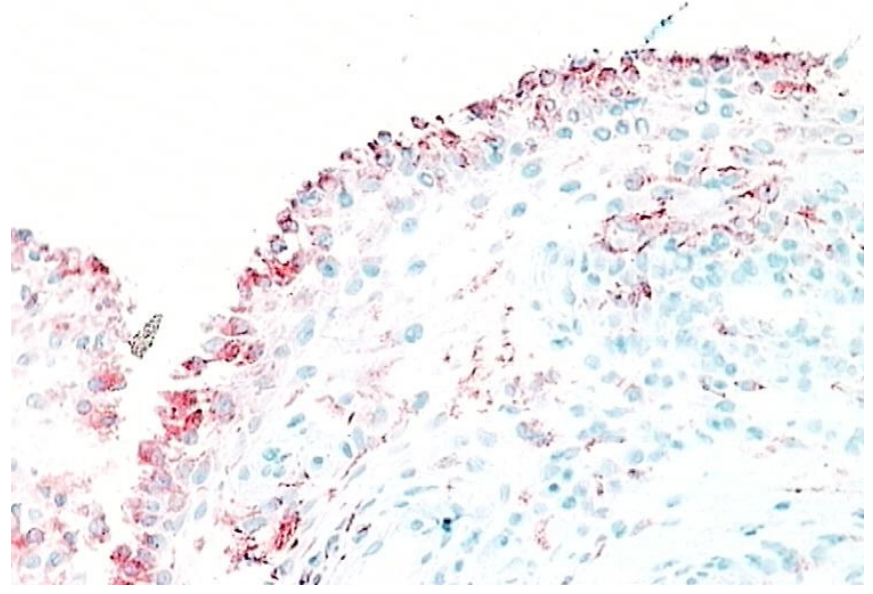

Fig. (6). RA synovial tissue (X 200) stained for $\mathrm{CD}^{+} 8^{+}$ macrophages (red). The majority of the lining layer cells in RA synovial tissue are of macrophage origin.

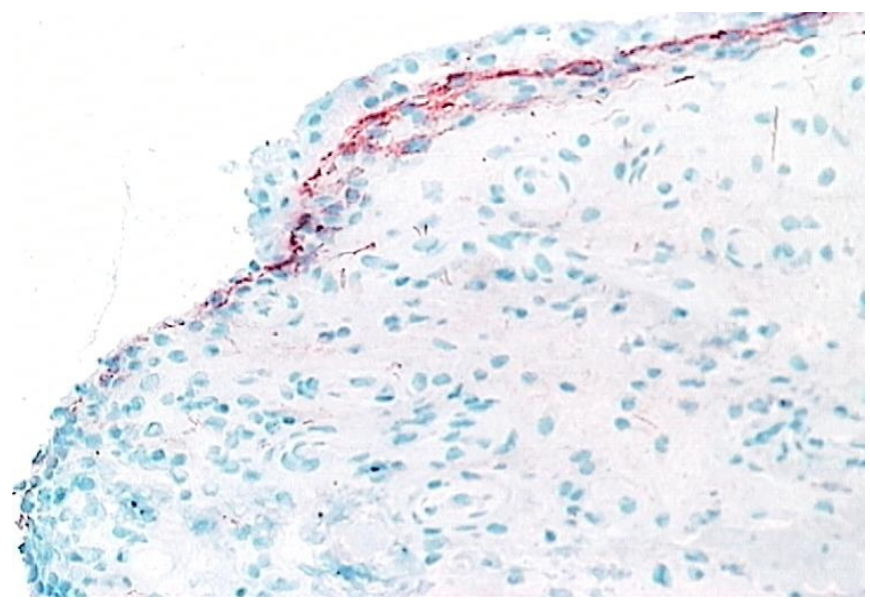

Fig. (7). RA synovial tissue (X 200) stained for CD55 ${ }^{+}$fibroblasts (red). Unlike normal synovial tissue, the lining layer of RA synovial tissue contains fewer fibroblast than macrophage lineage cells.

fibroblasts is reduced. Synovial intimal fibroblasts express CD55 (Fig. 5) and this marker can be used to distinguish intimal fibroblasts from intimal macrophages $[1,2,16]$. Cell suspensions generated from inflamed synovium and grown in tissue culture display fibroblast characteristics and ramifying processes with production of high levels of metalloproteinases [17]. It is not known whether the source of these cells is from intimal or subintimal fibroblasts. Collagenase and gelatinase expression is variable and not necessarily confined to intimal fibroblasts. Synovial intimal fibroblasts express several adhesion molecules, including vascular cell adhesion molecule-1 (VCAM-1), intercellular adhesion molecule (ICAM)-1, CD44 and $\beta_{1}$ integrins [1]. VCAM-1 expression (Fig. 8) is particularly unusual as it is absent from most other normal fibroblast populations, whereas CD44 and $\beta_{1}$ integrins can be expressed at lower levels on normal fibroblasts [1, 2, 18]. VCAM-1 expression on intimal fibroblasts may be important in cellular trafficking. The ligand for VCAM- $1, \alpha_{4} \beta_{1}$ integrin, is present on mononuclear leukocytes but not granulocytes, so the presence of VCAM-1 on type B synoviocytes in inflammatory arthritis may trap macrophages and lymphocytes within the synovial membrane while allowing neutrophils to egress into the synovial fluid. Complement receptor-2 (CR2, CD21) can be induced on synovial fibroblasts (but not other fibroblasts) in culture, although it is not expressed by normal intimal fibroblasts [19]. Decay accelerating factor (DAF), VCAM-1 and CR2 are all involved in B lymphocyte survival. Intimal fibroblasts are thought to arise by division within synovium either as a discrete self-replicating population, distinct from subintimal fibroblasts, but more likely they are replaced from the subintima. If synovial fibroblasts are disaggregated and cultured in vitro, they lose VCAM-1 and CD55 expression but the majority, apparently including cells of subintimal origin, will readily express these markers following cytokine stimulation. It seems likely, therefore, that synovial fibroblasts in both the intima and subintima belong to a specialized cell population with a propensity to express VCAM-1 and CD55.

\section{OTHER SUB-INTIMAL CELL POPULATIONS}

Two recent studies have demonstrated the range of cells which can be found in the subintimal regions of the normal synovial membrane $[2,3] . \mathrm{CD}^{+} \mathrm{T}$ cells, including $\mathrm{CD} 4^{+}$and $\mathrm{CD} 8^{+}$cells, can be found within the normal synovial tissue. Some of these cells have memory $\mathrm{T}$ cell phenotype and while they are likely to be simply trafficking through the normal synovium, their role, if any, in the homeostasis of synovial tissue is unknown. It is also possible to detect B cells, plasma cells and granzyme B positive cells in normal synovium, although they are present in small numbers [1-3].

\section{INTIMAL MATRIX}

The intimal matrix has an amorphous or fine fibrillar ultrastructure, containing collagens III, IV, V and VI with little type I collagen. Laminin, fibronectin and chondroitin-6sulfate-rich proteoglycan are all found in the intimal matrix and are all components of basement membrane (along with collagen IV), but there is no basement membrane beneath the intimal layer in normal synovium $[20,21]$. This may be due to the absence of entactin, which normally links other components in basement membrane together. Intimal microfibrils include: fibrillin-1 microfibrils, forming a basketwork around cells, and collagen VI microfibrils which 
form a uniform mesh. There are large amounts of hyaluronan mainly in the intimal and superficial subintimal layers of normal synovium which disappears in the deeper subintimal layer. This may indicate diffusion of hyaluronan (HA) from the surface towards clearing lymphatics.

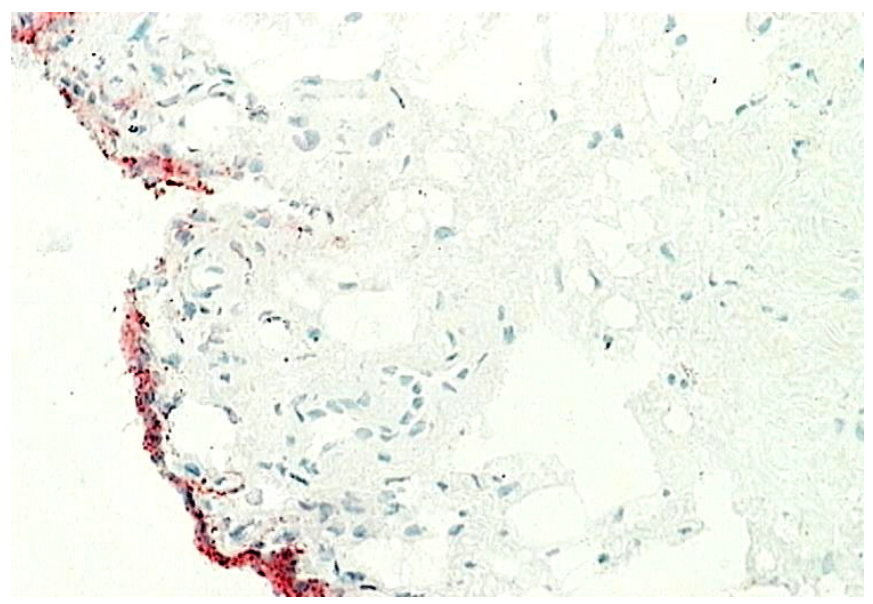

Fig. (8). Normal synovium (X200 magnification) stained for VCAM-1 (stained red).

\section{THE VASCULAR NET}

Capillaries occur just below or within the intima (Fig. 9). Some capillaries are fenestrated and fenestrae tend to face the tissue surface; while small venules are prominent deeper within the normal synovium $[6,22]$. Deeper still in the subintimal layer there are larger venules together with arterioles and lymphatics (Fig. 10), forming an anastomosing array [7]. Vessels with lymphatic staining characteristics are prominent in RA synovium and it has been proposed that failure of lymphatic drainage of synovial fluid may be a cause of villous proliferation in RA synovial tissue. If this is correct, it is likely to be due to overloading of existing lymphatic channels with HA-rich extracellular fluid and leukocytes rather than a lack of lymphatic channels. Apart from the fenestration of superficial capillary endothelial cells there is little evidence of specialization in synovial endothelium. Endothelial cells enlarge in inflamed tissue and microvascular proliferation can occur but these events are common to inflammation at many sites. Tissue-specific adhesion molecules or "addressins" have been sought but no evidence of synovium specific vascular markers have been found. However, there remains the possibility that specialized lymphocyte trafficking pathways apply to synovium, possibly based on chemokine-receptor interactions.

\section{THE NERVE SUPPLY}

Normal synovial tissue has a rich nerve supply [24, 25], including the sympathetic nervous system [26] most of the nerve supply is around vascular networks although it does extend into the intimal layers. Consistently reduced nerve supply is seen in synovial tissue from RA patients, especially in the more superficial intimal regions.

\section{CYTOKINE PRODUCTION IN NORMAL SYNOVIUM}

Although inflammatory cytokine production can be detected in normal synovial tissue [1-3], including

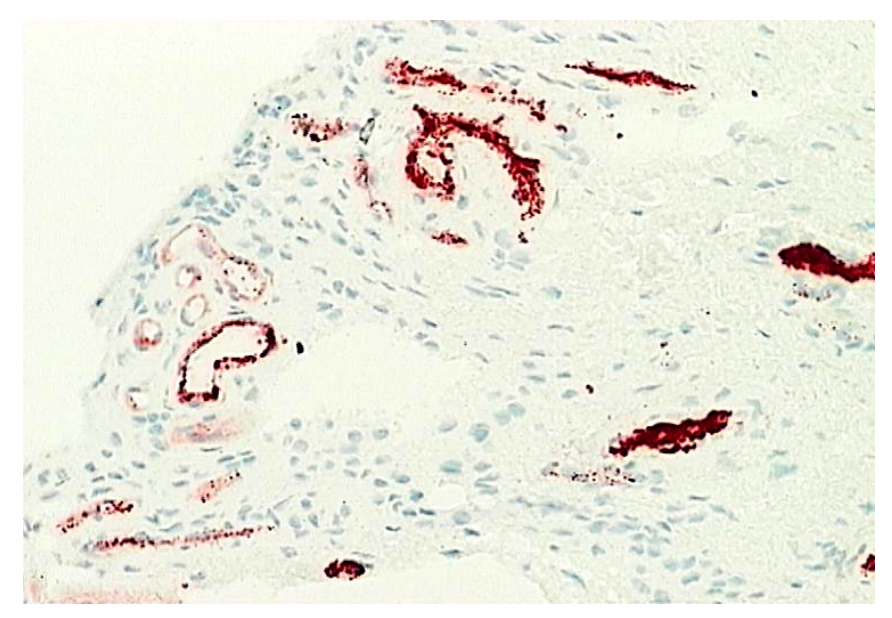

Fig. (9). Normal synovium (X200 magnification) stained with factor VIII (red) to demonstrate the vascular network.

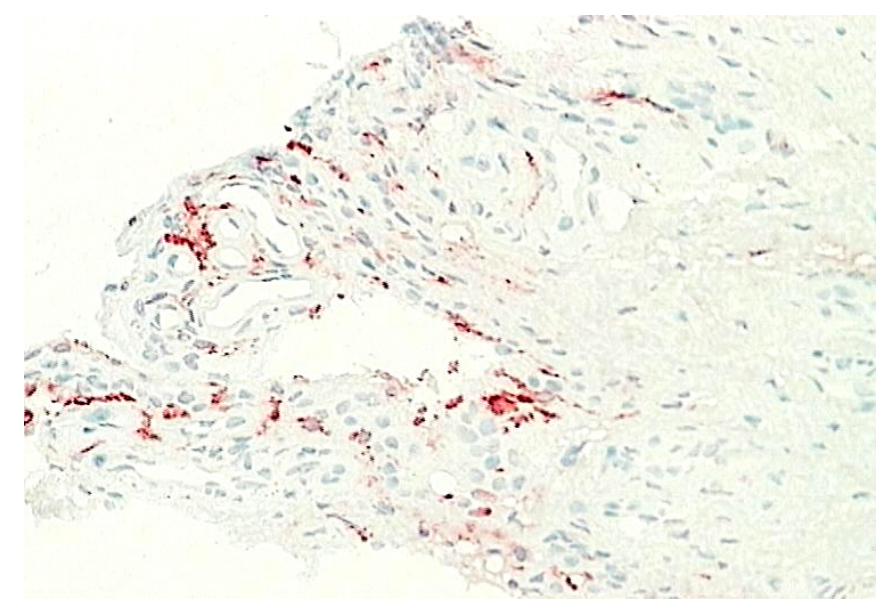

Fig. (10). Normal synovium (X200 magnification) stained with LYV-1 antibody (red) to demonstrate the lymphatic network.

interleukin-1 (IL-1) (Fig. 11), interleukin-6 (IL-6) and tumor necrosis factor alpha (TNF- $\alpha$ ) (Fig. 12), it is far less than that seen in inflamed synovial tissue such as in RA patients and the amount of anti-inflammatory cytokine production, at least in the case of IL-1 receptor antagonist (the naturally occurring inhibitor of IL-1), is far greater than the amount of inflammatory cytokine seen (Fig. 13). This would achieve the desired result of suppressing an inflammatory process in the normal synovium $[1,2]$. Similarly, the amount of receptor activator of NF kappa B ligand (RANKL) (an essential factor for the development of osteoclasts) seen in normal synovial tissue is low $[1,2]$ and far less than that of osteoprotegerin, the naturally occurring inhibitor of RANKL (Fig. 14). The net result of this will be to suppress the formation of osteoclasts with the normal synovium and preserve homeostasis within the normal joint.

\section{FUNCTION OF THE NORMAL SYNOVIUM}

The normal synovium provides a deformable packing that allows movement of adjacent, relatively non-deformable tissues $[1,23]$. Areolar synovium may also have specialized viscoelastic properties for coping with the stretching, rolling and folding it undergoes during joint movement. The additional functions of the normal synovium include maintenance of an intact non-adherent tissue surface, 
lubrication of cartilage, control of synovial fluid volume and composition and nutrition of chondrocytes within joints.

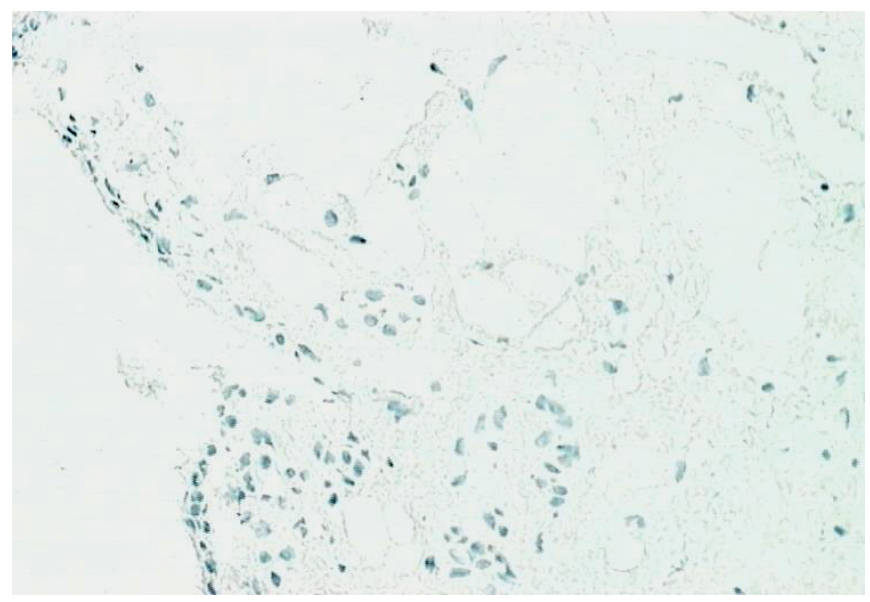

Fig. (11). Normal synovium (X200 magnification) stained with an antibody to detect the IL-1 $\beta$ (positive staining red). No IL-1 $\beta$ evident in normal synovial tissue.

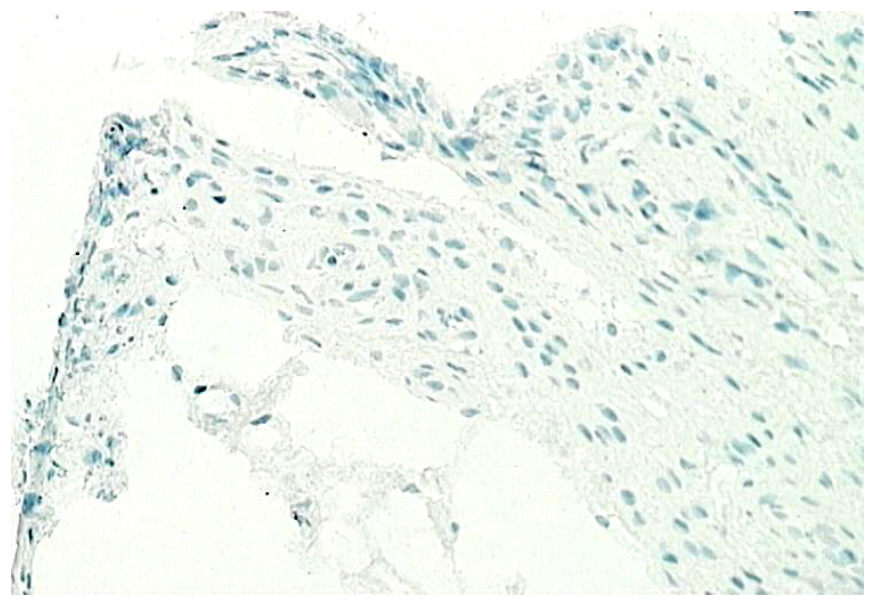

Fig. (12). Normal synovium (X200 magnification) stained with an antibody to detect the TNF- $\alpha$ (positive staining red). No TNF- $\alpha$ seen in normal synovial tissue.

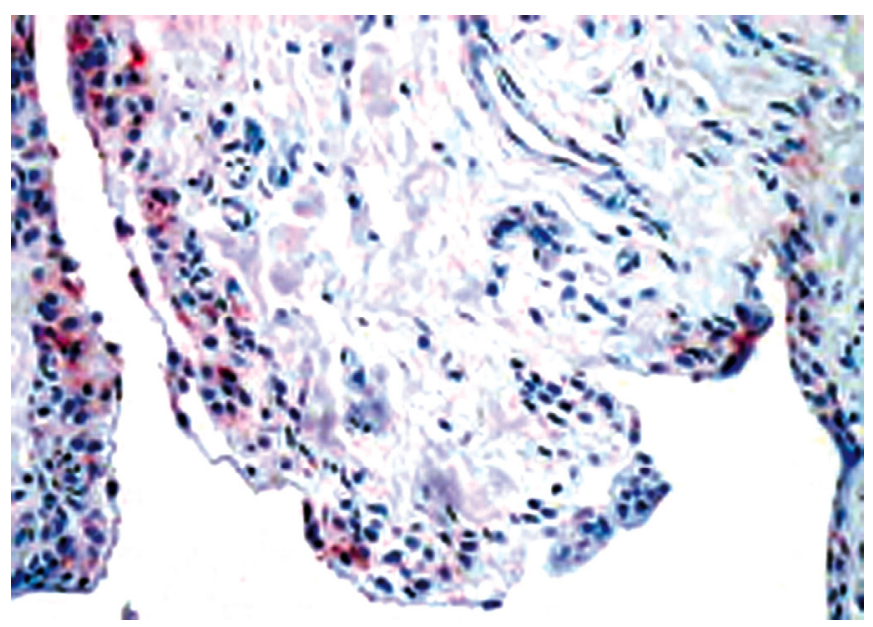

Fig. (13). Normal synovium (X200 magnification) stained with an antibody to detect the IL-1 receptor antagonist (red). IL-1 receptor antagonist mainly expressed by the lining layer macrophages.

\section{MAINTENANCE OF THE TISSUE SURFACE}

Synovial surfaces must be non-adherent to allow continued movement. The production of hyaluronan by intimal fibroblasts may be important in inhibiting adhesion. Plasminogen activator and DAF from intimal fibroblasts may also inhibit fibrin formation and scarring. To retain synovial fluid, the intimal matrix must allow free exchange of crystalloids and proteins but inhibit rapid transit of the viscous hyaluronan solution that is an important component of the fluid. These functions presumably reflect the combined activities of the intimal macrophages and fibroblasts. The vasculature is probably important in both intimal cell nutrition and recruitment of new cells. New macrophages will be derived from blood monocytes which enter the tissue through venules and perivascular fibroblasts may provide the main pool of intimal fibroblast precursors.

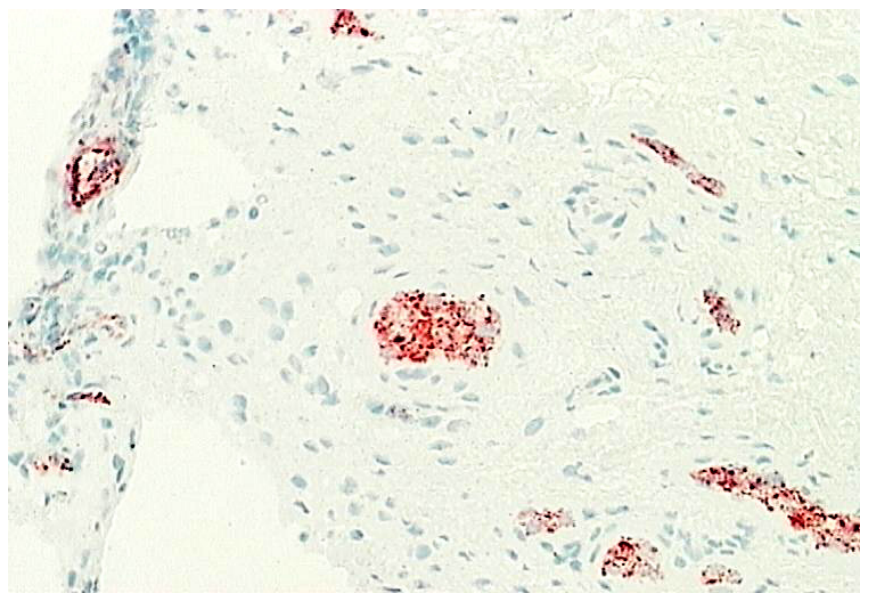

Fig. (14). Normal synovium (X200 magnification) stained with an antibody against osteoprotegerin (red), a naturally occurring inhibitor of osteoclast formation. Most of the OPG is expressed by endothelial cells lining blood vessels.

\section{LUBRICATION}

The ability of synovial fluid to lubricate cartilage surfaces is dependent on the presence of glycoprotein, especially a glycoprotein known both as 'lubricin' and 'superficial zone protein' because of its localization to the surface of both synovium and cartilage [27]. Hyaluronan does not appear to contribute to the ability of synovial fluid to lubricate cartilage in ex vivo systems but hyaluronan may be important in maintaining a film of lubricant on the cartilage surfaces in vivo. Hyaluronan is probably the main factor responsible for retaining a constant volume of fluid during exercise [28]. This constant volume is probably important as a cushion for synovial tissue and as a reservoir of lubricant for cartilage. It is likely that the rate of synthesis of hyaluronan and its exportation into the synovial fluid compartment are dependent on the mechanical stimulation of intimal fibroblasts and is influenced by the effectiveness of the synovial fluid cushion. Thus when synovial fluid volume is high, mechanical stresses on intimal fibroblasts are reduced with a resultant reduction in the rate of hyaluronan production and vice versa.

Joint effusions may result from mechanical irritation by worn bone and cartilage, with normal composition of synovial fluid and excessive production of hyaluronan by 
intimal fibroblasts stimulated by frictional forces, such as in osteoarthritis. The cause of joint effusions in an inflammatory synovitis is likely to be due to an accumulation of exudate similar to a pleural effusion, i.e. an overspill from the inflammatory edema in synovial tissue created by increased vascular permeability. However recent evidence suggests that low-grade inflammatory and immune reaction may contribute to the pathogenesis of osteoarthritis, suggesting that these two mechanisms of effusion development may not be as distinct as originally thought [29].

\section{CHONDROCYTE NUTRITION}

The synovium provides the major route of nutrition for chondrocytes. In normal joints a surprisingly large proportion of hyaline cartilage lies within $50 \mathrm{~mm}$ of a synovial surface. In any one position only a small proportion of cartilage is apposed to the other articular surface and synovium packs most of the space between less congruent areas. In immature joints the subchondral plate is incomplete and may contribute to nutrition but in adult joints this route is unlikely to be significant. Nutrition of areas of cartilage that do not come into close contact with synovium must take an indirect route. This is most relevant to concave articular surfaces. Nutrition may occur by smearing of a thin film of fluid over these surfaces during movement. However, the amount of nutrient carried this way is small. Indirect routes through cartilage matrix and the apposed articular cartilage may be more important. While the synovial blood vessels provide the most direct route for cartilage nutrition, there is no evidence that they are structurally adapted to this function.

\section{THE SYNOVIUM AS A SITE FOR PATHOLOGY IN INFLAMMATORY JOINT CONDITIONS}

Synovial joints are involved in a number of immunological and inflammatory disorders, including RA, systemic lupus erythematosus and spondyloarthritis. Understanding the microarchitecture of the normal synovium, including the wide range of microscopic appearance, cellular infiltrates and production of cytokines, enzymes and other biologically relevant proteins, will assist in understanding the relevant changes in synovial tissue architecture and immunopathology in disease states. While the architecture of the normal synovium is not as homogeneous as previously portrayed in rheumatology textbooks, there are consistencies across the broad spectrum of normal synovial tissues which can be contrasted with that seen in the chronically inflamed synovial tissue. The marked increase in synovial lining layer thickness, with a reverse of normal ratio of type A to type B synoviocytes, favoring type $B$ cells in normal synovium and type A cells in RA, is an example of this. Numerous other examples can be given including the changes in subintimal cell content, cytokine and chemokine production, vascular and lymphatic changes as well as production of metalloproteinases and stimulators of osteoclast formation. It is important to try and understand the hierarchy and chronology of these synovial changes in chronic inflammatory arthritides and contrast them with that seen in the normal synovium, to identify suitable therapeutic targets at various stages in the evolution of a chronic inflammatory arthritis. The identification of TNF- $\alpha$ and IL-
$1 \beta$ as two likely therapeutic targets is an example of how such a strategy can lead to useful therapeutic interventions being introduced into the management of several chronic inflammatory arthritides including RA, psoriatic arthritis and ankylosing spondylitis. There is still much to be learned about the immunological microenvironment of articular tissues, particularly the normal synovium.

\section{REFERENCES}

[1] Smith MD, Walker JG. The synovium. Rheumatology Editors Hochberg, Silman, Smolen, Weinblatt, Weisman, Eds. $5^{\text {th }}$ ed. 2011; vol 1: pp. 51-6.

[2] Smith MD, Barg E, Weedon H, et al. The microarchitecture and protective mechanisms in synovial tissue from clinically and arthroscopically normal knee joints. Ann Rheum Dis 2003; 62: 303-7.

[3] Singh JA, Araysi T, Duray P, Schumacher HR. Immunohistochemistry of normal human knee synovium: a quantitative study. Ann Rheum Dis 2004; 63: 785-90.

[4] Key JA. The synovial membrane of joints and bursae. In: Special cytology. New York: PB Hoeber 1932; vol. 2: pp. 1055-76.

[5] Davies DV. The structure and function of the synovial membrane. BMJ 1950; 1(4645): 92-5.

[6] Wilkinson LS, Edwards JCW. Microvascular distribution in normal human synovium. J Anat 1989; 167: 129-36.

[7] Xu H, Edwards J, Banerji S, Prevo R, Jackson DG, Athanasou NA. Distribution of lymphatic vessels in normal and arthritic human synovial tissues. Ann Rheum Dis 2003; 62: 1227-9.

[8] Mapp PI. Innervation of synovium. Ann Rheum Dis 1995; 54: 398403.

[9] Barland P, Novikoff AB, Hamerman D. Electron microscopy of the human synovial membrane. J Cell Biol 1962; 14: 207-16.

[10] Henderson B, Revell P, Edwards JCW. Synovial lining cell hyperplasia in rheumatoid arthritis : dogma and fact. Ann Rheum Dis 1988; 47: 348-9

[11] Edwards JCW, Wilkinson LS. Immunohistochemistry of synovium In: Henderson B, Edwards JCW, Pettifer ER, Eds. Mechanisms and models in rheumatoid arthritis. New York: Academic Press; 1995 pp. 133-150.

[12] Bhatia A, Blades S, Cambridge G, Edwards JCW. Differential distribution of FcgRIIIa in normal human tissues and colocalization with DAF and fibrillin-1: implications for immunological microenvironments. Immunology 1998; 94: 56-63.

[13] Poulter LW, Janossy G. The involvement of dendritic cells in chronic inflammatory disease. Scand J Immunol 1985; 21: 401-7.

[14] Wilkinson LS, Worrall JG, Sinclair HS, Edwards JCW Immunohistochemical reassessment of accessory cell populations in normal and diseased human synovium. Br J Rheumatol 1990; 29: 259-63.

[15] Wilkinson LS, Pitsillides AA, Worrall JG, Edwards JCW. Light microscopic characterisation of the fibroblastic synovial lining cell (synoviocyte). Arthritis Rheum 1992; 35: 1179-84.

[16] Stevens CR, Mapp PI, Revell PA. A monoclonal antibody (Mab 67) marks type B synoviocytes. Rheumatol Int 1990; 10: 103-6.

[17] Krane SM, Goldring SR, Dayer JM. Interactions among lymphocytes, monocytes and other synovial cells in the rheumatoid synovium. Lymphokines 1982; 7: 75-87.

[18] Edwards JCW. Synovial intimal fibroblasts. Ann Rheum Dis 1995; 54: 395-7.

[19] Leigh RD, Cambridge G, Edwards JCW. Expression of B cell survival cofactors on synovial fibroblasts. Br J Rheumatol 1996; 1(Suppl): 110 .

[20] Revell PA, Al-Saffar N, Fish S, Osei D. Extracellular matrix of the synovial intimal cell layer. Ann Rheum Dis 1995; 54: 404-7.

[21] Ashhurst DE, Bland YS, Levick JR. An immunohistochemical study of the collagens of rabbit synovial interstitium. J Rheumatol 1991; 18: 1669-72.

[22] Suter ER, Majno G. Ultrastructure of the joint capsule in the rat: presence of two kinds of capillaries. Nature 1964; 202: 920-1.

[23] Edwards JCW. Functions of synovial lining. In: Henderson B, Edwards JCW, Eds. The synovial lining in health and disease. London: Chapman \& Hall 1987; pp. 41-74. 
[24] Pereira da silva JA, Carmo-Fonseca M. Peptide containing nerves in human synovium: immunohistochemical evidence for decreased innervations in rheumatoid arthritis. J Rheumatol 1990; 17: 1592-9

[25] Mapp PI, Kidd BL, Gibson SJ, et al. Substance P-, calcitonin generelated peptide- and C-flanking peptide of neuropeptide Yimmunoreactive fibres are present in normal synovium but depleted in patients with rheumatoid arthritis. Neuroscience 1990; 37: 14353.

[26] Widenfalk B. Sympathetic innervations of normal and rheumatoid synovial tissue. Scand J Plast Reconstr Surg Hand Surg 1991; 25: $31-3$.
[27]

Jay GD, Britt DE, Cha CJ. Lubricin is a product of megakaryocyte stimulating factor gene expression by human synovial fibroblasts. J Rheumatol 2000; 27: 594-600.

[28] Levick JR. Fluid movement across synovium in healthy joints: role of synovial fluid macromolecules. Ann Rheum Dis 1995; 54: 41723.

[29] Pelletier JP, Martel-Pelletier J, Abramson SB. Osteoarthritis, an inflammatory disease: potential implication for the selection of new therapeutic targets. Arthritis Rheum 2001; 44: 1237-47.

Received: March 27, 2011

Revised: October 7, 2011

Accepted: October 11, 2011

(C) Malcolm D. Smith; Licensee Bentham Open.

This is an open access article licensed under the terms of the Creative Commons Attribution Non-Commercial License (http://creativecommons.org/licenses/by-nc/

3.0/) which permits unrestricted, non-commercial use, distribution and reproduction in any medium, provided the work is properly cited. 